\title{
ARQUIVOS DOCUMENTAIS E EXPERIÊNCIAS MISSIONÁRIAS NA AMAZÔNIA: UM ESTUDO DE CASO SOBRE A ATUAÇÃO DOS ESPIRITANOS EM TEFÉ NAS PRIMEIRAS DÉCADAS DO SÉCULO XX.
}

\author{
Documentary archives and missionary experiences in the Amazon: A case study on spirituality \\ in Tefé in the first centuries of the twentieth century.

\section{Tenner Inauhiny Abreu* Jubrael Mesquita Oliveira**}

\begin{abstract}
Resumo: O presente artigo, na esteira das ações realizadas a partir do projeto "História, arquivo e memória de Tefé", financiado pela FAPEAM e com a finalidade de organizar e democratizar o acervo da Prelazia de Tefé/AM, localizado na Rádio Educação Rural do município, tem como objetivo apresentar parte da documentação existente nos arquivos, destacando suas singularidades e potencialidades para os estudos históricos regionais e/ou nacionais. Além disso, pretende descrever aspectos constitutivos de uma relevante fonte primária presente no Acervo documental da Rádio. O manuscrito, escrito em idioma francês, produzido a partir da atuação de missionários franceses Espiritanos, entre 1914 e 1939 constitui-se em diário das visitações religiosas, denominadas pelos próprios clérigos de "desobrigas". Estes relatos dos religiosos em missão no território do Médio e Alto Amazonas, sob influência da administração eclesiástica da Igreja católica são importantes vestígios, sob a ótica da instituição a respeito das comunidades amazônicas e suas populações, nas primeiras décadas do século XX.
\end{abstract}

Palavras-chave: História, Arquivo, Tefé.

Abstract: This article, in the wake of the actions carried out from the project "History, archive and memory of Tefé", financed by FAPEAM and with the purpose of organizing and democratizing the collection of the Prelature of Tefé /AM, located in the Rural Education Radio of the municipality, aims to present part of the existing documentation in the archives, highlighting their singularities and potentialities for historical regional and / or national studies. In addition, it intends to describe constitutive aspects of a relevant primary source present in the Radio Collection documentary. The manuscript, written in the French language, produced from the work of French Espirituary missionaries, between 1914 and 1939 is a diary of religious visits, called by the clergymen themselves. These reports of religious on mission in the territory of the Middle and Upper Amazon, under the influence of the ecclesiastical administration of the Catholic Church, are important vestiges from the perspective of the institution regarding the Amazonian communities and their populations in the first decades of the twentieth century.

Keywords: History, Archive, Tefé.

\footnotetext{
* Doutorando do Programa de Pós-Graduação em História da Universidade de Brasília-PPGHIS-UnB e Professor da Universidade do Estado do Amazonas.

** Mestre em Geografia Humana atuando na linha de Desenvolvimento Regional e Urbano pela Universidade Federal de Santa Catarina - UFSC e Professor da Universidade do Estado do Amazonas.
} 


\section{CONSIDERAÇÕES INICIAIS}

É notória a importância dos arquivos para a sociedade como um todo. Explorados de variadas formas, os documentos preservados, organizados e disponibilizados ao público em geral, e aos pesquisadores em particular, têm possibilitado recuperar dimensões históricas e culturais de sociedades passadas.

Em que pese esse caráter salutar, muitos documentos do passado eventualmente têm chegado à atualidade mediante um processo de "entulhamento". Não é raro identificar espaços cujos acervos se encontram desorganizados, não higienizados e, numa situação mais grave, em processo de desintegração.

Existem esforços acadêmicos em diversas áreas ${ }^{1}$, em especial na história, de mobilizar energia no sentido de modificar essa realidade que se faz presente em várias regiões do país. Recentemente, no Amazonas, vários projetos foram desenvolvidos visando à organização e disponibilização de acervos documentais, assentados em editais de agência de fomento e/ou instituições de ensino superior. ${ }^{2}$

O presente artigo, na esteira das ações realizadas a partir do projeto "História, arquivo e memória de Tefé", financiado pela FAPEAM e com o foco na organização e democratização do acervo da Prelazia de Tefé/AM, localizado na Rádio Rural do município, tem como objetivo apresentar parte da documentação existente no acervo, notadamente os registros paroquiais e os periódicos, destacando suas singularidades e potencialidades para os estudos históricos regionais e/ou nacionais.

\section{O PROJETO: HISTÓRIA, ARQUIVO E MEMÓRIA DE TEFÉ/AM}

No segundo semestre de 2013, professores ligados à Universidade do Estado do Amazonas - UEA, atuando no Centro de Estudos Superiores de Tefé, submeteram coletivamente ao edital n. 010/2013 - PRÓ-ACERVO (Programa de apoio à organização, restauração, preservação e divulgação de acervos documentais do Estado do Amazonas), lançado pela Fundação de Amparo à Pesquisa do Estado do Amazonas (FAPEAM), um

\footnotetext{
${ }^{1}$ Como, por exemplo, Arquivologia, Biblioteconomia, entre outras.

2 Como o projeto "Documentos históricos do Judiciário amazonense: diagnóstico de acervo e organização do arquivo permanente do Poder Judiciário do Estado do Amazonas" (PGCT-FAPEAM), com a finalidade de organizar 15 mil processos (SILVA et. al., 2012). Além desse, existe o projeto "Colégio Amazonense D. Pedro II: memória, patrimônio e fontes históricas", financiado pela FAPEAM através do Edital 010/2013 PRÓACERVO com o objetivo de organizar o acervo documental do Colégio Amazonense D. Pedro II, entre outros.
}

- CANOA DO TEMPO - Arquivos documentais e experiências missionárias na Amazônia: um estudo de caso sobre a atuação dos espiritanos em Tefé nas primeiras décadas do século XX. 
projeto $^{3}$ cuja finalidade consistia na organização, preservação e democratização do acervo localizado na Rádio Educação Rural de Tefé, sob a guarda da Prelazia da cidade.

A documentação presente no acervo retrata aspectos da história das cidades do Alto e Médio Solimões ${ }^{4}$, em especial Tefé. A relevância desta cidade na região remonta ao seu passado $^{5}$, sobretudo pela sua posição estratégica. Foi alvo de ações missionárias (Carmelitas X Jesuítas) e disputas territoriais profundas, especialmente entre Portugal e Espanha (UGARTE, 2000; BOXER, 1977; MAXWELL, 1996).

A atuação missionária da igreja católica na região foi inconteste. No período colonial, as ordens religiosas, notadamente como já mencionamos, carmelitas, jesuítas, mas também franciscanos, dentre outros, disputavam as áreas para suas Coroas. Os carmelitas para Portugal e os jesuítas para a Espanha, com atuação efetiva causaram impactos significativos sobre as etnias indígenas, provocavam constantemente, deslocamentos das mesmas ao longo do rio Solimões. Do mesmo modo, os agentes coloniais leigos entravam em conflito com os povos indígenas, em especial para escravizá-los e direcioná-los para a extração das chamadas "drogas do sertão" (SANTOS, 2002).

Com efeito, os conflitos ligados ao avanço dos missionários (catequização) e colonos leigos (busca de mão de obra) não se encerraram no século XVIII. Avançaram nos séculos subsequentes, particularmente no XIX e XX. Por exemplo, no século XIX, uma nova ordem passou a ter influência na região, desta vez eram os espiritanos. Atualmente ainda marcam presença no local.

Neste sentido, o acervo da Prelazia de Tefé possui documentos do final do século XVIII e sobretudo dos séculos XIX e XX. Livros de batismo, casamento, óbitos, periódicos e demais peças documentais que acabam retratando de alguma forma a história da região do Alto e Médio Solimões. ${ }^{7}$ Ciente da importância do material presente no acervo, esforços foram canalizados para sua preservação e democratização (TEIXEIRA, Et. All. 2013). Tais documentos podem ser utilizados para a recuperação da história e da(s) memória(s) da região, para além da história/memória oficial da igreja e/ou cidades da Amazônia.

\footnotetext{
${ }^{3} \mathrm{O}$ projeto intitula-se "História, arquivo e memória de Tefé". O financiamento obtido foi da ordem de R\$ $66.593,33$

${ }^{4}$ Em especial Tefé, Alvarães, Uarini, Fonte Boa, Jutaí, Tonantins entre outras.

${ }^{5}$ Passado ligado ao mundo colonial, entre os séculos XVII e XVIII.

${ }^{6}$ São produtos extraídos da floresta - como, cacau, canela, baunilha, cravo, etc. - e exportados para a Europa. Sobre a mão de obra indígena e sua exploração para a extração das "drogas do sertão" ver também (SOUSA, 2002).

${ }^{7}$ Antigamente a área de Tefé abrangia o Médio e parte do Alto Solimões. Portanto os documentos do século XIX e início do século XX também registram aspectos de cidades localizadas nessa região da calha do rio.
} 
As ações do projeto, já desenvolvidas, resultaram na constituição de um inventário parcial dos documentos presentes no acervo. São aproximadamente 2.774 documentos organizados em 30 caixas de arquivos, distribuídos em diversos temas: documentos, cartas, jornais, livros, apostilas, mapas, relatórios, livros de ponto, atas de reuniões, cursos, formulários, projetos, informativos, boletins, encartes, programas de rádio, cadernos sobre os movimentos sindicais, etc. não contando com os que não foram catalogados e inseridos no inventário. Alguns desses materiais são significativos do ponto de vista de suas possibilidades de pesquisa histórica.

\section{DOCUMENTOS PAROQUIAIS}

Identificou-se uma gama de documentos que emergiram da presença histórica da igreja católica na região amazônica. Tratam-se de livros de batismos, casamentos e assentamentos de óbitos.

IMAGEM 1

LIVRO DE BATISMO, VILA DE EGA ${ }^{8}-1800$

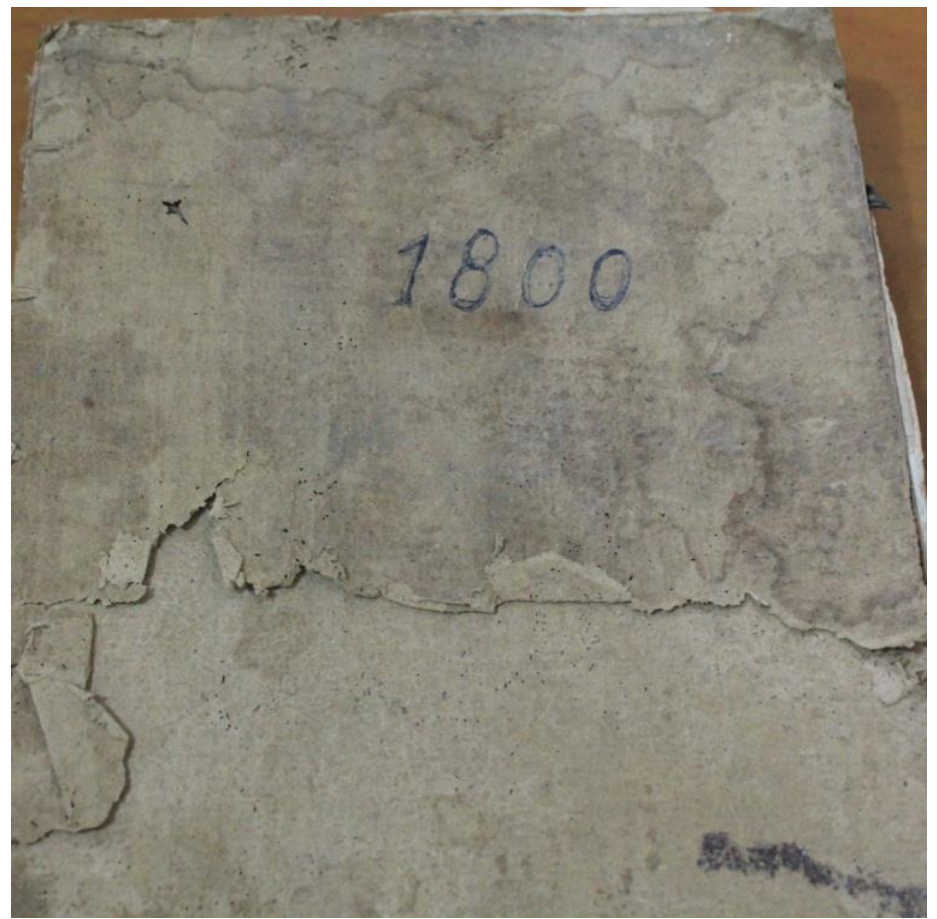

Fonte: Prelazia de Tefé. Seção de documentação.

\footnotetext{
${ }^{8}$ Tefé, cidade amazônica, nasceu de uma missão carmelita no início do século XVIII, especificamente 1718. A partir do Diretório dos Índios de 1757, a missão foi transformada em Vila, com denominação de Ega. Para conhecer essa história ver (FAULHABER, 1998; AZEVEDO, 1990; REIS, 1999).
}

LCANOA DO TEMPO - Arquivos documentais e experiências missionárias na Amazônia: um estudo de caso sobre a atuação dos espiritanos em Tefé nas primeiras décadas do século XX. 
A imagem acima trata do livro de assentos de batismos das vilas de Ega e Vila de Nogueira, a partir de 1798, até fins dos anos 1830. Contém diversos registros com anotações com referências a designação das nações indígenas da região à época. Esse tipo de documentação é vista como significativa para os estudos históricos, pois se colocam como importantes pistas para o processo de reconstrução de complexas relações sociais, articuladas no século XIX. Por ela, é possível, por exemplo, reconstituir redes de relações entre variados grupos (comerciantes, indígenas, escravizados e/ou libertos, etc.), assinalando suas características e dinâmicas.

Cabe destacar que esse tipo de material pode ser intensamente explorado regionalmente. Documentos paroquiais são peculiares pelo seu caráter repetitivo e por tratar, de forma bastante individualizada, da vida dos paroquianos. Nesses papéis se encontram informações salutares, tais como nome, filiação, naturalidade, qualidade social (cor, título), moradia, status social, entre outros (LIBBY, 2010: 41). Tal documentação ainda pode esclarecer questões ligadas à estratificação social, sistema de parentescos, relações de vizinhança, sistema de casamentos, etc.

Consoante João Fragoso é possível mediante os registros paroquiais realizar uma história demográfica ou das famílias (2014: 80). Mas se articulados a outros documentos, como jornais, revistas, boletins e demais, podem ainda fornecer uma série de informações relevantes.

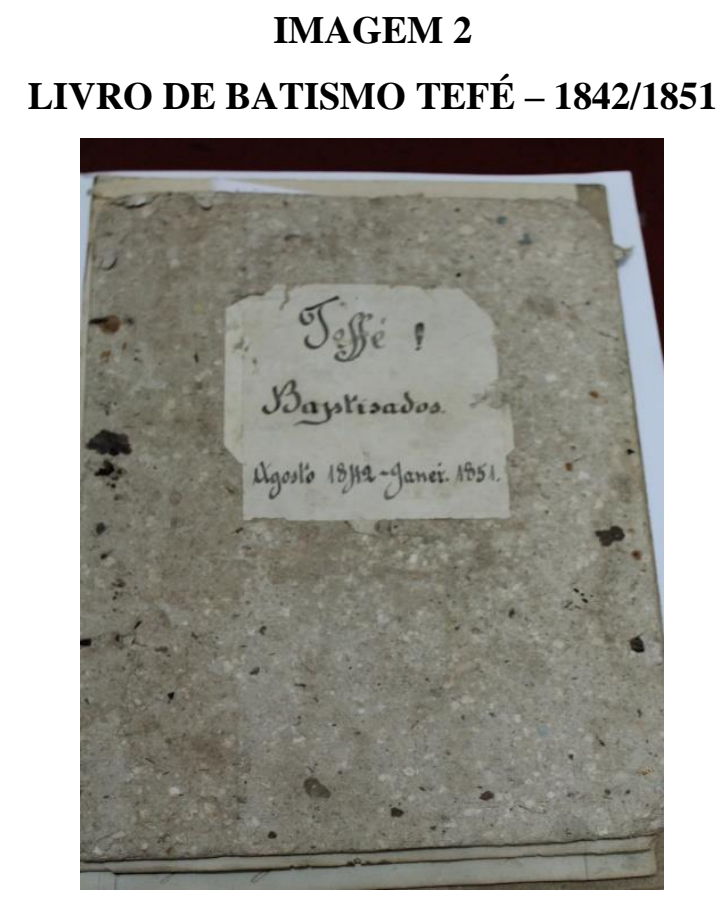

Fonte: Prelazia de Tefé. Seção de documentação. 
A imagem acima constitui-se em livro de assentos de batismos de Tefé, em período anterior a instalação da província do Amazonas. Também assinala as etnias indígenas de batizados, presentes nos registros, entre outros indivíduos, destaca-se a presença significativa de batizados com "pai incógnito", entre indivíduos sem descrição social (se livre ou liberto) ou cor (o que faz com que se deduza que sejam brancos).

Dos vários exemplos que são possíveis identificar, optou-se por salientar o estudo de Douglas Libby (2010). Este autor examinou a documentação paroquial de Minas Gerais durante o século XVIII, procurando analisar as representações identitárias e o processo de racialização envolvendo escravos e ex-escravos na região. Constatou que é possível observar uma mudança na descrição da origem e condição dos indivíduos naquele período. Usando os documentos paroquiais, o autor chegou à conclusão de que tais representações estariam mais vinculadas à posição social do que a própria identidade racial. Significativo na obra de Libby foi o uso da documentação paroquial na análise de racialização e posição social dos grupos estudados por ele.

Com efeito, os historiadores sociais têm explorado, embora de maneira menos intensa do que em outros países, os registros paroquiais. Internacionalmente, existe um largo uso dessa documentação que pode servir como referência para estudos internos e regionais (FRAGOSO, 2010: 74).

\section{PERIÓDICOS}

Além dos documentos paroquiais, encontram-se também periódicos. Jornais, revistas e boletins compõem também o acervo da Prelazia de Tefé.

\section{IMAGEM 3}
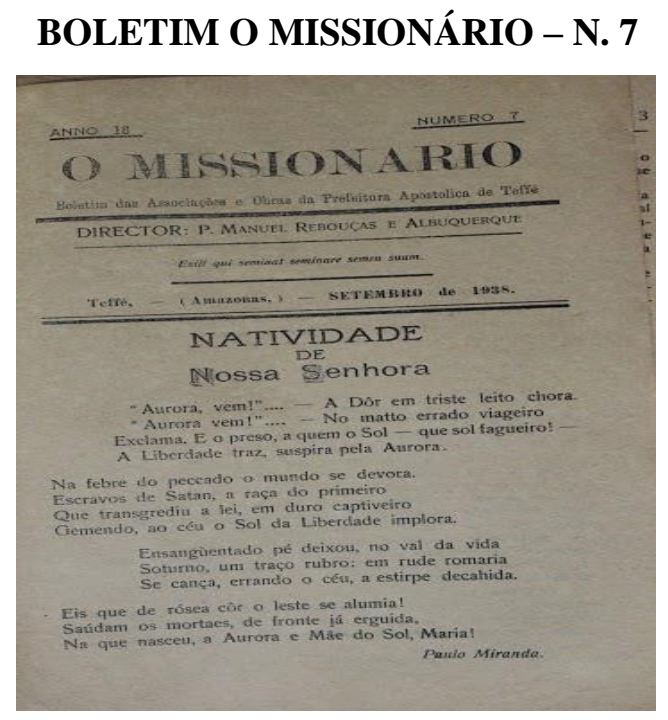

LCANOA DO TEMPO - Arquivos documentais e experiências missionárias na Amazônia: um estudo de caso sobre a atuação dos espiritanos em Tefé nas primeiras décadas do século XX. 
Fonte: Prelazia de Tefé. Seção de documentação.

A imagem acima é referente ao boletim "O missionário" que circulou na cidade de Tefé, a partir dos anos 1930, e que traz o cotidiano da ação missionária da igreja católica neste período. Aspectos vinculados ao cenário nacional estão presentes na fonte, como criticas ao então interventor do Estado do Amazonas, Álvaro Maia, ou discussões em relação a defesa do ensino religioso na educação no novo regime.

O uso de periódicos na disciplina histórica foi gradativamente tomando corpo, em especial nas últimas quatro décadas. Tornaram-se material empírico de grande potencialidade na reflexão histórica. Isso se deu, grosso modo, quando a história tradicional e o foco dado ao documento produzido pelos órgãos oficiais do Estado foram criticados enquanto hegemônicos (CARDOSO, 1981; BORGES, 1980; BARROS, 2004).

Como resultado disso, revistas, jornais diários, boletins, entre outros, foram explorados no sentido de potencializar a recuperação de aspectos significativos do passado das sociedades. Nesse processo de uso dos periódicos, há quem tenha assinalado sua relevância:

Manancial dos mais férteis para o conhecimento do passado, a imprensa possibilita ao historiador acompanhar o percurso dos homens através dos tempos. O periódico, antes considerado fonte suspeita e de pouca importância, já é reconhecido como material de pesquisa valioso para o estudo de uma época (CAPELATO, 1988: p. $13)$.

Embora destacando a imprensa, não se pode negar a importância dessa assertiva para os periódicos em geral, uma vez que eles trazem em seu bojo férteis informações que podem lançar luzes sobre dimensões sociais importantes como, por exemplo, a trajetória de lutas, os interesses, os ideais de grupos sociais que estão presentes na cena histórica em específicos contextos e lugares do passado.

Tais documentos potencializam uma reflexão histórica significativa das sociedades no nível de suas condições de vida, manifestações culturais, políticas, dentre outros. Inserindo-os em seus contextos históricos, identificando os grupos por traz dos periódicos e seus "discursos", dimensões sociais e culturais importantes podem ser iluminadas (LUCA, 2005; ZICMAN, 1985). 


\section{ARQUIVO/HISTÓRIA: PRESERVAÇÃO E MEMÓRIA}

Certamente que nas sociedades contemporâneas os esforços voltados para a constituição de arquivos, pautados na seleção de documentos ${ }^{9}$, porém salutares na preservação de informações e conteúdos, em especial institucionais, relacionam-se não somente com a preocupação de cumprir uma legislação específica ${ }^{10}$, mas também de preservação de memórias (JARDIM, 1995).

Recentemente, a questão do patrimônio histórico e cultural ganhou corpo, como destacou Fratini:

É cada vez maior a preocupação com a conservação e a preservação do patrimônio histórico e cultural de uma sociedade, de um país. As dimensões e as características que definem o nosso tempo e espaço geram discussões constantes sobre o que, como e para quem preservar (2009: 1).

Como parte significativa desse processo, os arquivos foram mencionados, por serem formados por documentos legados de outras épocas e, neste sentido, inseridos como elementos que formam o patrimônio histórico e cultural. Portanto, atualmente o interesse em preservá-los vai muito além do Estado e de suas instituições, envolvendo a sociedade civil como um todo.

Com efeito, não se pode negar que o processo de preservação e constituição de arquivos abarca questões ligadas à memória histórica, particularmente quando se opera a seleção dos documentos. O que preservar? Que documentos merecem ser legados a posteridade? E por quê?

Essas perguntas revelam um movimento no sentido de fazer emergir uma memória que, dependendo do grupo, da instituição ou da entidade, será diferente. Um exemplo bastante notório se refere ao Estado Nacional que sempre buscou traçar memórias oficiais em diferentes contextos (BREFE, 2005).

Por outro lado, documentos que foram produzidos, porém jamais pensados para a posteridade ou para compor algum tipo de memória oficial, quando descobertos podem

\footnotetext{
${ }^{9}$ Nem tudo é preservado. Não obstante, os documentos que escaparam da destruição e do esquecimento se enquadraram em torno de critérios específicos que nortearam esse processo. Nesses critérios se materializaram interesses sociais, políticos, econômicos e culturais hegemônicos em contextos diferentes (REIS, 2006).

${ }^{10}$ Lei n. 8159 , de 8 de janeiro de 1991. Dispõe sobre a política nacional de arquivos públicos e privados e dá outras providências.
}

LANOA DO TEMPO - Arquivos documentais e experiências missionárias na Amazônia: um estudo de caso sobre a atuação dos espiritanos em Tefé nas primeiras décadas do século XX. 
apontar para o surgimento de outras memórias, muitas vezes incômodas, reforçando seu caráter plural, revelando conflitos e disputas (POLLAK, 1989: 4-8).

Um exemplo de uma "memória incômoda" corresponde aos arquivos das ASI Universitárias. Motta recuperou a trajetória dos arquivos das Assessorias de Segurança e Informações das universidades e os embates e disputas que eclodiram nesse caminho. Para o autor, controlar "a memória coletiva sempre foi um mecanismo de exercício de poder, de garantir e conferir legitimidade aos governantes e aos sistemas de organização política em vigor..." (MOTTA, 2008: 43-44).

A importância dada aos arquivos levou diversos pesquisadores de diferentes áreas arquivologia, antropologia, história e outras - a realizarem estudos, sob diferentes perspectivas (COOK, 1998; ROUSSO, 1996; CHUVA, 1995).

Neste sentido, o projeto desenvolvido e direcionado ao acervo da Prelazia de Tefé, assim como o presente texto, surgiu no sentido de reforçar esse movimento de preservação e democratização, mas também de demonstrar que alguns (existem muitos outros que ainda serão observados e mencionados) documentos desse acervo podem revelar diferentes histórias e memórias sobre a região amazônica.

\section{A PRESENÇA DA IGREJA CATÓlICA EM TEFÉ NAS PRIMEIRAS DÉCADAS DO SÉCULO XX}

As missões religiosas chegadas ao Brasil no início do século $\mathrm{XX}$ estabeleceram suas bases de atuação social e missionária principalmente em cidades. Destacam-se no norte do Brasil os capuchinhos, os salesianos e os espiritanos, como veremos.

Tal perspectiva pode ser percebida a partir da criação e instalação das Prefeituras Apostólicas. Esta estrutura administrativa deu base posterior para a constituição de prelazias e dioceses. (PIRES, 2002)

Pode-se inferir daí a chamada ação missionária desenvolvida em cidades, tendo como um dos seus objetivos a evangelização e educação para os mundos do trabalho. Desta maneira, como assinala Pires (2002), o trabalho missionário para a Amazônia brasileira desempenhou importante papel, no que a autora denomina de afirmação territorial do Estado e na nacionalização da população, além do processo de urbanização de espaços de fronteira.

Em se tratando da trajetória da igreja católica na Amazônia, sua presença deixou marcas visíveis, não apenas em testemunhos e documentos eclesiásticos, mas também no seu aparelho administrativo e nas vivências cotidianas das comunidades do interior da região. Conforme assinalado por Pires (2002), em 1910, o papa Pio X criou três Prefeituras 
Apostólicas no Brasil, sendo a primeira sediada em Tefé-AM e entregue a ordem dos Espiritanos franceses, outra em São Paulo de Olivença-AM, a cargo dos Capuchinhos italianos da Umbria e por último, no Alto Rio Negro organizada pelos Salesianos. As três únicas Prefeituras apostólicas criadas no Amazonas, ficavam em áreas de fronteira.

Tal preocupação da administração eclesiástica na região, como destaca a autora, não para aí. As Prefeituras Apostólicas passaram a ser Prelazias (Alto Rio Negro em 1928, Tefé e São Paulo de Olivença em 1950). As prefeituras Apostólicas são definidas por Hortal apud Pires (2002) como dioceses de segunda ordem em territórios sem hierarquia ordinária. Se observarmos, por exemplo, o processo de desmembramento da Diocese de Manaus e criação da denominada Prefeitura Apostólica de Tefé no ano de 1910, pode-se inferir a atuação efetiva e constante institucional da Igreja Católica.

Importante salientar que a região do médio Solimões no atual Estado do Amazonas teve papel relevantemente destacado ao longo dos séculos, principalmente pela sua condição de espaço de fronteira, o que não escapava à administração central do catolicismo, ao deslocar inúmeras ordens religiosas para o Amazonas e para a cidade de Tefé. Tal cidade, localizada no interior do Estado do Amazonas, até 1910 pertencia à circunscrição administrativa da Diocese de Manaus, quando na referida data é criada a Prefeitura Apostólica de Tefé, tendo como Prefeito Apostólico, o Espiritano francês Monsenhor Alfredo Michael Barrat, a partir do decreto da congregação consistorial de Pio X, como assevera Schaeken (1997).

A Prefeitura Apostólica de Tefé foi criada como já mencionado, juntamente com as de outras localidades: São Gabriel da Cachoeira, São Paulo de Olivença, como incentivo do então governo brasileiro para manter a região sob domínio nacional, compreendendo tais locais como estratégicos, o que implicaria na missão de ocupar e nacionalizar o território.

Conforme assinala Menezes (2012), neste processo as missões religiosas tinham um importante papel, que ia além da catequese de populações indígenas. As missões se estabeleceram, de acordo com a autora, nos núcleos e sedes municipais, sendo tais lugares pontos de encontro, fixação e fluidez que envolviam fronteiras, limites, Estados, administração, índios, missionários e nacionalização da população. Na cidade, a urbanização foi um instrumento eficiente dentro dessa política de ocupação e nacionalização do território. E foi justamente nesse momento quando da criação de Prefeituras apostólicas que essa região registrou importantes transformações em seu espaço urbano.

No inicio da criação da Prefeitura Apostólica, seu prefeito Monsenhor Barrat, transferiu a sede da Prefeitura, que antes ficava na Boca da Missão (no rio Tefé) para a sede 
do município. A partir desse momento a cidade registrou muitas transformações em seu espaço urbano, como construções de escolas, igrejas, ruas, serralherias, praças públicas, bem como outras construções sendo a mais famosa o Seminário São José que inicialmente era uma escola de formação dos padres locais e depois se tornou o Externato São José, sendo uma escola de formação para os meninos. (SCHAEKEN, 1997).

A influência da igreja católica na região do médio Solimões, notadamente em cidades do Interior do Estado do Amazonas, tais como Tefé, é sensível, principalmente se observarmos a promoção da chamada Prefeitura Apostólica para Prelazia em 1950, a pedido de seu primeiro Bispo, Monsenhor Joaquim de Lange, o que acabou resultando na criação de várias paróquias, no que era território da prelazia, e hoje se constituem em municípios: Carauari e Alvarães (1948), Foz do Jutaí (1950), Missão (1952), Itamarati (1958), Uarini (1969), Caitaú (1971), Maraã (1981), e a Paróquia de Fonte Boa (SCHAEKEN, 1997, p. 49).

\section{VIVÊNCIAS COTIDIANAS, VIDA CIVILIZADA E URBANA NOS ESPAÇOS AMAZÔNICOS.}

Como já mencionamos não pode ser negligenciada a presença da Igreja Católica na Amazônia. Seus projetos missionários têm como pano de fundo concepções de civilização, educação, trabalho e vida urbana. (PIRES, 2002).

A chegada de novas missões eclesiásticas na região amazônica, no início do século XX, modificou a organização territorial da igreja católica no Brasil, sendo como afirma Pires (2002), ausente de política missionária, tal atuação, no entanto era fortemente de caráter urbano. A autora destaca que na organização territorial sob influência administrativa católica, a estrutura missionaria é basicamente a da paróquia urbana.

Não pode-se deixar de aludir a duas necessidades que fazem parte das preocupações da igreja católica ao se fixar no interior da Amazônia, mais notadamente em cidades: Um aparato fixo para instalações de prédios de missões no núcleo urbano ou Aldeias, e a organização das desobrigas, que para Pires (2002) podem ser definidas como viagens constantes e sistematicamente organizadas para o interior dos municípios, em busca de maior conhecimento do espaço físico e das comunidades presentes no território. Tais atividades geralmente eram relatadas e constituíam em diários com descrições das atividades relacionadas ao dia a dia das comunidades visitadas e que descrevem aspectos relevantes do espaço urbano.

DESCRIÇÃO DA FONTE: O JORNAL DA MISSÃO DE TEFÉ, DATADO ENTRE 1914 E 1939 
Uma das fontes presentes no acervo documental da Rádio Educação Rural de TeféAM é um dos relatos de viagens feitos e registrado por missionários da ordem dos Espiritanos, denominadas de desobrigas. Em forma de diário intitulado "Jornal das comunidades missão Yeffé (sic) 1914-1938.”. Trata-se do quarto volume do que se auto denomina Jornal da Comunidade do Santo Espírito Boca do Tefé.

Tal documento é composto de 141 páginas, em perfeito estado de conservação, escrito na língua francesa, com algumas inserções em outras línguas. Pelo título, constitui um dos diários onde os missionários da Boca da Missão faziam anotações sobre suas viagens pelas comunidades do interior. Como a ordem dos Espiritanos é constituída de missionários franceses, alemães e holandeses alguns documentos encontram-se nestes idiomas.

No que tange a escrita, o autor tende a escrever as letras maiúsculas de I e $\mathrm{J}$ de maneira semelhante, dado que pode gerar confusões. Também utiliza em diversas passagens do manuscrito letras maiúsculas quando não é inicio de frases ou nomes. Pontos e vírgulas podem não ser diferentes, ou não ser visíveis. Outra característica do manuscrito e que em frente a um nome de pessoa, embarcação ou localidade, sua escrita varia, quanto a incidência do uso de letras maiúsculas. Tal tendência está presente ao longo de todo o documento. Numa das seções do Manuscrito encontramos a listagem de alguns missionários e suas localidades de atuação:

Pessoal da Missão Amazônica no final de 1915 Bocca do Teffé

- $\quad$ Monsenheur Alfredo Miguel Barrat, Prefeito Apostólico

- $\quad$ Padre Manoel d'Alencar, Ministério - Professor

- Irmãos Titus, Aristobule, Martin, Wilfrid, Emmanuel, Raphael Bonaventura Tefé

- $\quad$ Padre Cabrolié, Curé

Fonte Boa

- $\quad$ Padre J.B.P. Parissier, Curé

St Felippe

- $\quad$ Padre Louis Dornic, Curé

Tarauacá

- $\quad$ Padre Joseph Frisch XXX

$\mathrm{Na}$ Europa

- $\quad$ Padre José Cappe de J. Felippe, na guerra

- $\quad$ Padre Constantin Tatevin, na guerra

- $\quad$ Padre François Dargnat, doente

- $\quad$ Padre Cornelie, de férias, a guerra não o deixa voltar.

Cruzeiro do Sul

- Padre Alfonse Donnadieu, curé (Fonte: JORNAL DAS COMUNIDADES MISSÃO TEFFÉ, 1915, fl. 28. Manuscrito. Seção de Documentação Rádio Educação Rural de Tefé). 
Além dos nomes dos missionários pertencentes a missão dos Espiritanos em Tefé-AM, observa-se a expansão espacial da atuação destes religiosos, que abrangiam territorialmente o médio e Alto Amazonas, numa extensão territorial maior que o atual Estado de São Paulo!

Possivelmente um destes missionários é quem escreve no diário, notamos que dentre os nomes Emmanuel nunca é citado no texto (seria ele o autor?).

Acontecimentos mundiais aparecem ao menos indiretamente nas páginas do diário, como na citação acima, mencionando os padres presentes na Europa vinculados à missão na Amazônia, porém na Guerra.

Em 07 agosto de 1914 o documento faz alusão à notícia da guerra: “ 7 Agosto Chega o «Paes de Carvalho» indo para o Javary. O correio nos informa da notícia triste da guerra na Europa.” (Fonte: JORNAL DAS COMUNIDADES MISSÃO TEFFÉ, 1914 a 1938, fl. 47. Manuscrito. Seção de Documentação Rádio Educação Rural de Tefé).

Apesar da característica de diário com descrições breves, algumas passagens sinalizam aspectos do dia a dia da missão, bem como as preocupações com o Conflito Mundial:

29 Setembro Festa de São Miguel, Santo patroe (sic) de Monseigneur. O almoço é as 11:00, têm discursos - poesias, etc. Meio-dia XXX todo mundo vai para Teffé com a lancha levar 3000 tijolos e de la trazer uns 1000 telhas, de volta no anoitecer. Durante a noite passa o Padre Joseph Trapp chegando do Juruá (S. Felippe) forçado de ir para a guerra. (Fonte: JORNAL DAS COMUNIDADES MISSÃO TEFFÉ, 1914 a 1938, fl. 34. Manuscrito. Seção de Documentação Rádio Educação Rural de Tefé)

Além do lamento do cronista, que está de passagem para, a contra gosto ir para a guerra, o texto alude a material necessário para a manutenção e fixação da missão: tijolos e telhas, alusão recorrente no texto, juntamente com outros materiais de construção, em trocas realizadas na sede do município de Tefé. O próprio documento dá indicações do interesse dos missionários a respeito destes materiais: "Julho 2 Essa manhã chega o «Manauense» da casa «Andresen» com 40 toneis de cimento para nossa escola de Teffé (sic) doado pelo diretor da sociedade comercial amazonense. A tarde nós levamos esse toneis com 1400 tijolos para Teffé (sic).” (Fonte: JORNAL DAS COMUNIDADES MISSÃO TEFFÉ, 1914 a 1938, fl. 37. Manuscrito. Seção de Documentação Rádio Educação Rural de Tefé).

A missão contava não apenas com seus recursos, mas também com apoio de comerciantes da região, para a construção de escola em Tefé. A criação de redes clientelares de sustentáculo a atuação missionária. Mas não só os membros da Igreja influenciavam o espaço urbano da cidade, costumes e tradições indígenas da região eram incorporados ao dia a 
dia da missão, como a extração de castanha e o consumo de tartarugas: "28 de Abril Chega a lancha «Sultana» de Me. Cavalcante com 170 tartaruga para a Missão. O Padre Tatevin vai com essa lancha no Japurá fazer o ministério." (Fonte: JORNAL DAS COMUNIDADES MISSÃO TEFFÉ, 1914 a 1938, fl. 26. Manuscrito. Seção de Documentação Rádio Educação Rural de Tefé).

As vezes até mesmo a falta das tartarugas é sentida... "Dezembro Desce a lancha «Liberdade» do Japurá, traz informações sobre nosso homens da Praia do Mapary, parece que as tartaruga não querem aparecer. Alexandre manda uma para a esposa como amostra." (Fonte: JORNAL DAS COMUNIDADES MISSÃO TEFFÉ, 1914 a 1938, fl. 56. Manuscrito. Seção de Documentação Rádio Educação Rural de Tefé).

Tradições alimentares como consumo vinho, e carneiro aparecem nos relatos: "5 de Maio Vêm o «Javari» que leva em fim os famosos carneiros do Comandante Rabello que nos tinia deixado o ano passado para engordar, em vez de engordar a metade morreu e o resto não vale muito mais.” (Fonte: JORNAL DAS COMUNIDADES MISSÃO TEFFÉ, 1914 a 1938, fl. 30. Manuscrito. Seção de Documentação Rádio Educação Rural de Tefé).

As agruras das experiências da missão não são esquecidas pelo cronista como na passagem acima, a alusão ao estado de saúde dos missionários é frequente, bem como as festas tradicionais do interior não passam desapercebidas. "13 Junho Festa de São Antônio. $\mathrm{Na}$ Missão não tem nada especial. O dia anterior veio o famoso boi da vizinhança para brincar com as crianças." (Fonte: JORNAL DAS COMUNIDADES MISSÃO TEFFÉ, 1914 a 1938, fl. 43. Manuscrito. Seção de Documentação Rádio Educação Rural de Tefé).

Estas e outras informações contidas no diário das desobrigas, dão à história local, rostos e gostos, demonstram potencialidade ao narrarem cenas do cotidiano amazônico, e necessitam por isso mesmo serem transcritas e traduzidas, para que mais pesquisadores possam avaliar a potencialidade do documento.

Conforme ressalta Pires (2002) é pouco provável detectar diferenças nos procedimentos das ordens missionárias na Amazônia. O que se sabe, e pudemos comprovar em alguns trechos do manuscrito, é que frequentemente a missão dos Espiritanos no Brasil, dependeu de repasses de recursos não apenas de Dioceses, mas também de instituições e governos locais para se manter.

Pires (2002) demonstra, e as passagens do manuscrito transcrito e traduzido apontam, que efetivamente o trabalho missionário esteve concentrado espacialmente nos núcleos 
urbanos, sob a bandeira de evangelização, de jovens incentivados a migrarem para internatos e externatos (as nossas crianças de que fala o documento?).

A atuação da igreja católica enquanto instituição, deixou marcas não apenas no espaço urbano das cidades do interior do Amazonas, registrou em seus documentos, costumes, práticas culturais, vivências cotidianas em seus arquivos. Preservá-los e democratizar o acesso a estas fontes localizadas em cidades distantes no interior da Amazônia, lança luz sobre novos aspectos da história da região, sua multiplicidade de gentes e riqueza cultural.

\section{CONSIDERAÇÕES FINAIS}

Através das ações realizadas no âmbito do projeto "História, arquivo e memória de Tefé" (FAPEAM) foi possível identificar uma gama diversificada de documentos que compõem o acervo da Prelazia de Tefé/AM. Desse universo se buscou destacar, como exemplos, os documentos paroquiais e os periódicos para, a partir deles, explicitar suas peculiaridades e potencialidades para as pesquisas históricas e culturais acerca da região.

Como mencionado anteriormente, mediante os arquivos paroquiais questões ligadas à estratificação social, sistema de parentescos, relações de vizinhança e sistema de casamentos podem ser exploradas. Já com relação aos periódicos aspectos referentes às condições de vida, materiais e culturais, dinâmicas políticas, formas de circulação de ideias e tantos outros temas (que acabam emergindo das questões registradas e levantadas pelos periódicos) podem também serem alvos de pesquisas.

Desta forma, os documentos assinalados, assim como o conjunto deles, colocam-se como fundamentais para a região (e até mesmo numa escala maior, nacional e internacional), sobretudo para recuperar e fazer emergir novas histórias e memórias.

Nesta esteira, fica então evidente que a preservação, organização e democratização de acervos, como este desenvolvido em Tefé, são extremamente importantes para a compreensão histórica das sociedades do passado.

Enviado: 06/10/2018

Aceito: 25/01/2019

\section{REFERÊNCIAS BIBLIOGRÁFICAS}

AZEVEDO, João Lúcio de. O Marquês de Pombal e sua época. $2^{\mathrm{a}}$ ed., Lisboa: Clássica Editora, 1990.

BARROS, José D’Assunção. O Campo da História. Petrópolis: Vozes, 2004.

BORGES, Vavy Pacheco. O que é História? São Paulo: Brasiliense, 1980. 
BOXER, Charles. O Império Ultramarino Português. Lisboa: Edições 70, 1977.

BREFE, Ana Cláudia Fonseca. O Museu Paulista: Affonso Taunay e a memória nacional. São Paulo: Editora de Unesp; Museu Paulista, 2005.

CAPELATO, Maria Helena Rolim. Imprensa e História do Brasil. São Paulo: Contexto/Edusp, 1988.

CARDOSO, Ciro Flamarion. Uma introdução a História. São Paulo: Brasiliense, 1981.

CHUVA, Márcia (org.). A invenção do patrimônio: continuidade e ruptura na constituição de uma política oficial de preservação no Brasil. Rio de Janeiro: IPHAN, 1995.

COOK, Terry. Arquivos Pessoais e Arquivos Institucionais: para um entendimento arquivístico comum da formação da memória em um mundo pós-moderno. Estudos Históricos, n. 21, p. 129-149, 1998.

FAULHABER, Priscila. O Lago dos Espelhos. Etnografia do Saber sobre a Fronteira em Tefé/Amazonas. Belém: Museu Goeldi, 1998.

FRAGOSO, João. Efigênia Angola, Francisca Muniz forra parda, seus parceiros e senhores: freguesias rurais do Rio de Janeiro, século XVIII. Uma contribuição metodológica para a história colonial. Topoi, v. 11, n. 21, jul.-dez. 2010.

Arquivos paroquiais e história na América Lusa, séculos XVII e XVIII. $1^{\circ}$ ed. Rio de Janeiro: Maud X, 2014.

FRATINI, Renata. Educação patrimonial em arquivos. Histórica - Revista do Arquivo Público do Estado de São Paulo, n. 34, p. 1-11, 2009.

JARDIM, José Maria. A Invenção da Memória nos Arquivos Públicos. Ciência da Informação, vol. 25, n. 2, 1995.

LIBBY, Douglas Cole. A empiria e as Cores: Representações identitárias nas Minas Gerais dos Séculos XVIII e XIX. In: Escravidão, mestiçagens, populações e identidades culturais. São Paulo: Annablume Belo Horizonte: PPGH-UFMG; Vitória da Conquista: Edições UESB, 2010.

LUCA, Tânia Regina de. A história dos, nos e por meio dos periódicos. In: PINSKY, Carla Bassanezi (org.). Fontes Históricas. São Paulo: Contexto, 2005.

MAXWELL, Kenneth. O Marquês de Pombal. São Paulo: Paz \& Terra, 1996.

MOTTA, Rodrigo Pato Sá. Incômoda Memória. Os arquivos das ASI Universitárias. Acervo. Rio de Janeiro, vol. 21, n. 2, p. 43-66, jul./dez. 2008.

POLLAK, Michael. Memória, esquecimento, silêncio. Revista Estudos Históricos, v. 2, n. 3, p. 3-15, 1989.

REIS, Arthur Cézar Ferreira. Manáos e outras Villas. 2a . ed. rev. Manaus: Governo do Estado do Amazonas/ Secretaria de Estado da Cultura e Turismo/ Editora da Universidade do Amazonas, 1999. 
REIS, Luís. O arquivo e arquivística evolução histórica. Biblios, ano 7, n. 24, p. 1-11, abriljunho 2006.

ROUSSO, Henry. O Arquivo ou o indício de uma falta. Estudos Históricos, n. 17, p. 85-91, 1996.

SANTOS, Francisco Jorge dos. Além da Conquista: guerras e rebeliões indígenas na Amazônia Pombalina. $2^{\circ}$ ed. Manaus: EDUA, 2002.

SILVA, James Roberto, SOUZA, Denize da Mota, JANES, Natacha Oliveira, MACHADO, Rita de Cássia F. Organizando um arquivo histórico: um thesaurus para o Poder Judiciário do Estado do Amazonas e para a história. Acervo. Rio de Janeiro, v. 25, n. 1, p. 161-174, jan./jun. 2012.

SOUSA, James. Mão-de-obra indígena na Amazônia Colonial. Em Tempo de Histórias, n. 6, p. 1-18, 2002.

TEIXEIRA, Alcemir Arlejean Bezerra, TELES, Luciano Everton Costa, ABREU, Tenner Inauhiny de. Acervo, História e Memória de Tefé/AM: relato de um projeto de pesquisa. Revista Eletrônica Documento/Monumento, v. 10, p. 205-210, 2013.

UGARTE, Auxiliomar Silva. Filhos de São Francisco no País das Amazonas: catequese e colonização na Amazônia do séc. XVII. Amazônia em Cadernos, Manaus, v. 6, p. 201-228, 2000 .

ZICMAN, Reneé Barata. História Através da Imprensa: algumas considerações metodológicas. Projeto História. São Paulo, n. 4, p. 89-102, 1985.

Referências Bibliográficas

CLAVAL, P. A geografia cultural no Brasil. In: BARTHE-DELOIZY, F., and SERPA, A., orgs.Visões do Brasil: estudos culturais em Geografia [online]. Salvador: EDUFBA; Edições L'Harmattan, 2012, pp. 11-25.

FAGUNDES et alli. História da Igreja no Brasil. Ensaio de Interpretação a partir do Povo. Petrópolis: Editora Vozes, 1980.

FRAGOSO, João et al. Arquivos Paroquiais e História Social na América Lusa, séculos XVII e XVIII: métodos e técnicas da pesquisa na reinvenção de um corpus documental. Organização João Fragoso, Roberto Guedes e Antônio Jucá de Sampaio. $1^{\mathrm{a}}$ ed. Rio de Janeiro, Mauad X 2014.

HOORNAERT, Eduardo. A Igreja Católica no Brasil Colonial. In História da América Latina: América Colonial, Vol. I, Trad: Maria Clara Cescato. $2^{\mathrm{a}}$ Ed. Editora da Universidade de São Paulo, Brasília DF: Fundação Alexandre de Gusmão, 2012.

JOBIM, Anísio. Panoramas Amazônicos: III-Tefé. Typ Phenix, Manaus, AM, 1937.

LIBBY, Douglas Cole. A empiria e as Cores: Representações identitárias nas Minas Gerais dos Séculos XVIII e XIX. In: Escravidão, mestiçagens, populações e identidades culturais. São Paulo: Annablume Belo Horizonte: PPGH-UFMG; Vitória da Conquista: Edições UESB, 2010. 
LOSE, Alícia Duha. Edições de documentos históricos: A quem interessa? A quem se destinam? Revista da ABRALIN, v.16, n.2 p. 71-86, Jan./Fev./Mar./Abril de 2017.

OLIVEIRA, J. A. \& GUIDOTTI, PE. HUMBERTO. A Igreja Arma Sua Tenda na Amazônia. Manaus: editora da Universidade do Amazonas., 2000.

MEDEIROS, Wellington da Silva. Concílio Vaticano I (1869-1870): Centralização do Catolicismo. Revista eletrônica Discente História.com. Universidade Federal do Recôncavo da Bahia. Centro de Artes, Humanidades e Letras. Ano I, n.1, 2013.

MENEZES, Maria Lucia Pires. Prefeituras Apostólicas na Amazônia brasileira: Estado e Igreja na nacionalização do território. XII Colóquio de Geocrítica, Bogotá, Colômbia, 2012.

PIRES MENEZES, M.L. Trabalho e Território: as missões católicas no interior do estado do Amazonas, Brasil. Scripta Nova, Revista Electrónica de Geografía y Ciencias Sociales, Universidad de Barcelona, vol. VI, $\mathrm{n}^{\mathrm{o}} 119$ (11), 2002. Disponível em: http://www.ub.es/geocrit/sn/sn119-11.htm. Data de acesso: setembro de 2018

SANTOS, Francisco Jorge dos. Além da Conquista: guerras e rebeliões indígenas na Amazônia Pombalina. $2^{\circ}$ ed. Manaus: EDUA, 2002.

SCHAEKEN, Raimunda Gil. Centenário da presença espiritana na Prelazia de Tefé-Am (1897-1997), Manaus, AM, 1997.

REIS, ARTHUR. C.. A Conquista Espiritual da Amazônia. São Paulo: Escolas Profissionais Salesianas, 1942.

TELES, Luciano Everton Costa, TEIXEIRA, Alcemir Arlejean Bezerra, ABREU, Tenner Inauhiny de. Acervo, História e Memória de Tefé/AM: relato de um projeto de pesquisa. Revista Documento/Monumento. Vol. 10, nº 1, Dez. 2013, p. 205-210. 